in vivo $34: 1533-1539(2020)$

doi:10.21873/invivo.11942

\title{
The Clinical Significance of Lymphovascular Invasion in Gastric Cancer
}

\author{
HIROHITO FUJIKAWA ${ }^{1}$, KEISUKE KOUMORI ${ }^{1}$, HAYATO WATANABE ${ }^{1}$, KAZUKI KANO $^{1}$, YYTA SHIMODA ${ }^{1}$, \\ TORU AOYAMA ${ }^{2}$, TAKANOBU YAMADA ${ }^{1}$, TAMAGAWA HIROSHI ${ }^{2}$, NAOTO YAMAMOTO ${ }^{1}$, HARUHIKO CHO $^{3}$, \\ MANABU SHIOZAWA ${ }^{1}$, TAKAKI YOSHIKAWA ${ }^{4}$, SOUICHIRO MORINAGA ${ }^{1}$, YASUSHI RINO ${ }^{2}$, \\ MUNETAKA MASUDA $^{2}$, TAKASHI OGATA ${ }^{1}$ and TAKASHI OSHIMA ${ }^{1}$ \\ ${ }^{1}$ Department of Gastrointestinal Surgery, Kanagawa Cancer Center, Yokohama, Japan; \\ ${ }^{2}$ Department of Surgery, Yokohama City University, Yokohama, Japan; \\ ${ }^{3}$ Department of Gastric Surgery, Tokyo Metropolitan Cancer and \\ Infectious Diseases Center Komagome Hospital, Tokyo, Japan; \\ ${ }^{4}$ Department of Gastric Surgery, National Cancer Center Hospital, Tokyo, Japan
}

\begin{abstract}
Background/Aim: Lymphovascular invasion (LVI) is recognized as a prognostic predictor of recurrence in certain carcinomas. According to current Japanese guidelines, however, in gastric cancer, LVI is not clinically useful information, except for predicting the curability of endoscopic resection. We clarified the clinical significance of LVI in gastric cancer and its correlation with disease prognosis. Patients and Methods: A total of 2,090 cases of gastric cancer undergoing radical gastrectomy were enrolled. The correlation of LVI and other histopathological factors was evaluated with regards to patient prognosis. Results: LVI(+) was noted in 894 cases. A multivariate analysis showed that $p T, p N$, and LVI were independent risk factors for patient prognosis. In pT2-4 patients with nodal metastasis, a significant difference was revealed, and the 5year overall survival rates in $\mathrm{LVI}(+)$ cases were lower than those in LVI(-) (60.9\% vs. 76.7\%, p=0.005). Conclusion: LVI in gastric cancer is an independent prognostic factor, and tends to worsen prognosis, especially in advanced cancers with lymph node metastases.
\end{abstract}

Gastric cancer is the fifth-most common cancer and the third leading cause of cancer-related deaths worldwide (1). Every

This article is freely accessible online.

Correspondence to: Takashi Oshima, Department of Gastrointestinal Surgery, Kanagawa Cancer Center, 2-3-2 Nakao, Asahi-ku, Yokohama 241-8515, Japan. Tel: +81 455202222, Fax: +81 455202202, e-mail: oshimat@kcch.jp

Key Words: Gastric cancer, lymphovascular invasion, prognostic factor. year, 180,000 new cases of gastric cancer are diagnosed, and 45,000 die of this disease in Japan (2). Nodal metastasis is known to be an important prognostic factor and is an essential element in determining the classification of patients with gastric cancer $(3,4)$.

Lymphovascular invasion (LVI) is defined as the invasion of vessel walls by tumor cells and/or the presence of tumor emboli within an endothelial-lined space and this may be considered as the initial image finding for lymph node metastasis and other types of organ metastases. The predictive value and prevalence of LVI strongly depend on the type of cancer, and the presence of LVI is an accepted prognostic factor in many malignancies, such as breast cancer, urothelial carcinoma and colorectal cancer (5-7). In gastric cancer, the most reliable indication of prognosis can be obtained through assessment using TNM staging guidelines (8).

LVI, as represented by the $\mathrm{T}$ factor, $\mathrm{N}$ factor, and histology, is also an important pathological finding that should be evaluated after gastrectomy. However, according to the current guidelines for gastric cancer treatment in Japan, LVI is not clinically useful prognostic information. LVI is only clinically useful for the assessment of curability after endoscopic resection; if LVI is positive, additional surgical resection is recommended (9). In colorectal cancer, vascular invasion is defined as a high-risk factor for recurrence under the European Society for Medical Oncology (ESMO) guidelines, and used as a reference for postoperative adjuvant chemotherapy (10). Although small cohort studies have suggested that the presence of LVI is correlated with tumor recurrence and a low survival rate and is an independent indicator of a poor outcome in gastric cancer patients, the pathophysiological behavior of LVI is still unclear, and no consensus has been reached as to 
Table I. Clinicopathological characteristics of the 2,090 patients.

\begin{tabular}{|c|c|c|c|c|}
\hline Variables & Cases & $\begin{array}{l}\mathrm{LVI}(+) \\
(\mathrm{n}=894)\end{array}$ & $\begin{array}{c}\operatorname{LVI}(-) \\
(\mathrm{n}=1196)\end{array}$ & $p$-Value \\
\hline Age (years) & & & & $p<0.001$ \\
\hline$<65$ & 996 & $360(40.3 \%)$ & $636(53.2 \%)$ & \\
\hline$\geq 65$ & 1,094 & $534(59.7 \%)$ & $560(46.8 \%)$ & \\
\hline Median & 65 & & & \\
\hline Range & $24-87$ & $24-86$ & $26-87$ & \\
\hline Gender $\mathrm{n}(\%)$ & & & & $p=0.78$ \\
\hline Male & 1,431 & $615(68.8 \%)$ & $816(68.2 \%)$ & \\
\hline Female & 659 & $279(31.2 \%)$ & $380(31.8 \%)$ & \\
\hline $\begin{array}{l}\text { Tumor location - } \\
\mathrm{n}(\%)\end{array}$ & & & & n.p. \\
\hline $\begin{array}{l}\text { Upper third of } \\
\text { stomach }\end{array}$ & 489 & $261(29.2 \%)$ & $228(19.0 \%)$ & \\
\hline $\begin{array}{l}\text { Middle third of } \\
\text { stomach }\end{array}$ & 992 & $380(42.5 \%)$ & $612(51.2 \%)$ & \\
\hline $\begin{array}{l}\text { Lower third of } \\
\text { stomach }\end{array}$ & 609 & $253(28.3 \%)$ & $356(29.8 \%)$ & \\
\hline $\begin{array}{l}\text { Maximum tumor } \\
\text { diameter }\end{array}$ & & & & $p<0.001$ \\
\hline$<30 \mathrm{~mm}-\mathrm{n}(\%)$ & 739 & $168(18.8 \%)$ & $571(47.7 \%)$ & \\
\hline$\geq 30 \mathrm{~mm}-\mathrm{n}(\%)$ & 1351 & $726(81.2 \%)$ & $625(52.3 \%)$ & \\
\hline Median - mm & 60 & 45.5 & 30 & \\
\hline Range & $2-212$ & $5-212$ & $2-210$ & \\
\hline $\begin{array}{l}\text { Histologic type - } \\
\mathrm{n}(\%)\end{array}$ & & & & $p=0.88$ \\
\hline Differentiated & 630 & $271(30.3 \%)$ & $359(30.0 \%)$ & \\
\hline Undifferentiated & 1460 & $623(69.7 \%)$ & $837(70.0 \%)$ & \\
\hline $\begin{array}{l}\text { Depth of tumor } \\
\text { invasion }(\mathrm{T})-\mathrm{n}(\%)\end{array}$ & & & & $p<0.001$ \\
\hline Early (pT1) & 1,228 & $246(27.5 \%)$ & $982(82.1 \%)$ & \\
\hline Advance (pT2-4) & 862 & $648(72.5 \%)$ & $214(17.9 \%)$ & \\
\hline $\begin{array}{l}\text { Lymph node } \\
\text { metastasis }(\mathrm{N})- \\
\mathrm{n}(\%)\end{array}$ & & & & $p<0.001$ \\
\hline $\mathrm{N}-$ & 1,434 & $365(40.8 \%)$ & $1069(89.4 \%)$ & \\
\hline $\mathrm{N}+$ & 656 & $529(59.2 \%)$ & $127(10.6 \%)$ & \\
\hline
\end{tabular}

whether LVI affects the long-term survival of gastric cancer patients or not (11-15). Given the above, research exploring the clinical utility of LVI in gastric cancer through a large cohort study is important.

The aim of this study was to clarify the clinical significance of LVI in gastric cancer by evaluating the relationship between LVI and clinicopathological features and outcomes in patients with gastric cancer.

\section{Patients and Methods}

Patients. A total of 2,090 patients were selected from the prospective consecutive database of the Kanagawa Cancer Center between January 2000 and December 2013 based under the following criteria: 1) histologically proven adenocarcinoma of the stomach; 2) patients diagnosed with clinical T1-T4; 3) patients having no M1 disease; 4) patients receiving radical surgery with
Table II. Correlation between lymph node metastasis $(N)$ and lymphatic vessel invasion $(L)$ and venous invasion $(V)$.

\begin{tabular}{lcccccc}
\hline Variables & Cases & $\mathrm{N}(+)$ & $\mathrm{N}(-)$ & Odds ratio & $95 \% \mathrm{CI}$ & $p$-Value \\
\hline $\mathrm{L}$ & & & & & & \\
$(+)$ & 595 & 422 & 173 & 8.44 & $6.65-10.70$ & $p<0.001$ \\
$\quad \mathrm{~V}^{(-)}$ & 1,495 & 234 & 1261 & & & \\
$(+)$ & 697 & 416 & 281 & 3.70 & $2.93-4.68$ & $p<0.001$ \\
$(-)$ & 1,393 & 240 & 1153 & & & \\
\hline
\end{tabular}

basically D1 or further lymphadenectomy, including patients who have been diagnosed with non-curative resection after undergoing endoscopic submucosal dissection (ESD) according to the Japanese gastric cancer treatment guidelines (9); and 5) patients who had received preoperative and/or postoperative adjuvant chemotherapy. Patients with metachronous and synchronous double cancer were excluded, as were those with residual gastric cancer.

Histopathological evaluations. All surgical specimen were processed according to standard pathological procedures and stained with hematoxylin and eosin (H\&E). At least two pathologists examined the primary tumor and regional lymph node staining slides. The depth of tumor invasion was T1 for early cancer and T2$\mathrm{T} 4$ for advanced cancer. With regard to histological types, papillary, well-differentiated and moderately differentiated adenocarcinomas were considered as differentiated type, and poorly differentiated adenocarcinoma, signet ring cell carcinoma and mucinous carcinoma were considered as undifferentiated type. LVI was defined as the invasion of vessel walls by tumor cells and/or the presence of tumor emboli within an endothelial-lined space, with no distinction between vascular and lymphatic vessels (16). The diagnosis of LVI was classified using TNM classification of malignant tumors eighth edition, (17) as follows: L0, no lymphatic invasion; L1, lymphatic invasion is observed; V0, no venous invasion; V1, microscopic venous invasion is observed; V2, macroscopic venous invasion is observed. However, this classification method is somewhat less objective, and the evaluation may not be consistent among pathologists. Therefore, in the present study, L0 and V0 were defined as $\mathrm{L}(-)$ and $\mathrm{V}(-)$, respectively, and $\mathrm{L} 1$ and V1-2 were defined as $\mathrm{L}(+)$ and $\mathrm{V}(+)$, respectively. Furthermore, L(-) and V(-) were defined as LVI-negative [LVI(-)], and $\mathrm{L}(+)$ and/or $\mathrm{V}(+)$ was defined as LVI-positive [LVI(+)].

Statistical analyses. Continuous variables were tested using the Student's $t$-test and shown as the mean \pm standard deviation. Categorical variables were analyzed using the Chi-squared test and logistic regression analysis. Univariate and multivariate analyses of risk factors for the overall survival (OS) after surgery were performed using Cox proportional hazards models, and the results were expressed in terms of the hazard ratio (HR) and corresponding $95 \%$ confidence interval (CI). The OS rates were calculated using the Kaplan-Meier method, and the log-rank test was used to analyze between-group differences in survival rate.

A $p$-value less than 0.05 was considered statistically significant, and all statistical tests were two-sided. Analyses were performed using the statistical software program 'EZR' (Easy R) version 1.40 (18). 
Table III. Univariate and multivariate analyses of prognostic factors in 2,090 patients with gastric cancer for overall survival.

\begin{tabular}{|c|c|c|c|}
\hline Variables & Cases & $\begin{array}{c}\text { Univariate analysis } \\
\text { HR }(95 \% \mathrm{CI}) \\
p \text {-Value }\end{array}$ & $\begin{array}{c}\text { Multivariate analysis } \\
\text { HR }(95 \% \mathrm{CI}) \\
p \text {-Value }\end{array}$ \\
\hline
\end{tabular}

\begin{tabular}{lccc}
\hline $\begin{array}{c}\text { Depth of tumor } \\
\text { invasion (T) }\end{array}$ & & & \\
Early (pT1) & 1,228 & $3.796(3.112-4.631)$ & $2.343(1.829-3.002)$ \\
$\begin{array}{c}\text { Advance } \\
(\mathrm{pT} 2-4)\end{array}$ & 862 & $p<0.001$ & $p<0.001$ \\
Lymph node & & & \\
metastasis (N) & & & \\
$\mathrm{N}-$ & 1,434 & $3.458(2.874-4.162)$ & $1.926(1.537-2.415)$ \\
$\mathrm{N}+$ & 656 & $p<0.001$ & $p<0.001$ \\
Lymphovascular & & & \\
invasion & & & $1.289(1.022-1.627)$ \\
$\mathrm{LVI}(-)$ & 1,196 & $2.787(2.303-3.374)$ & $p=0.03$ \\
$\mathrm{LVI}(+)$ & 894 & $p<0.001$ & \\
\hline
\end{tabular}

\section{Results}

Clinicopathological characteristics of LVI in gastric cancer patients. A total of 2,090 patients were entered into this study, of which 894 (42.8\%) had LVI. In the LVI(+) group, 595 cases were $\mathrm{L}(+)$, and 697 cases were $\mathrm{V}(+)$. Table I shows the clinicopathological characteristics of all 2,090 patients. The median age was 65 years, the proportion with LVI was higher in those aged 65 and older. There were no significant differences in the sex, tumor location or histological type, but clear differences were found in the maximum tumor diameter, depth of tumor invasion $(\mathrm{T})$ and lymph node metastasis $(\mathrm{N})$. A total of $25.5 \%$ of patients had no lymph node metastasis with LVI, and $80.6 \%$ had lymph node metastasis without LVI. The risk factors for lymph node metastasis were compared for lymphatic invasion and venous invasion, and lymphatic invasion showed a higher odds ratio, but both lymphatic invasion and venous invasion had a strong correlation with LNM (Table II).

Prognostic impact of the clinicopathological findings. Table III shows the results of an analysis of the correlation with the OS by adding LVI to the T- and $\mathrm{N}$-factors that have been used for conventional progression classification. As a result, LVI(+) was an independent poor prognostic factor as well as $\mathrm{T}$ and $\mathrm{N}$ factors in univariate and multivariate analyses $(\mathrm{HR}=1.29,95 \% \mathrm{CI}=1.02-1.63, p=0.03)$. The 5-year survival rate was $91.2 \%(95 \% \mathrm{CI}=89.4 \%-92.7 \%)$ in the $\mathrm{LVI}(-)$ group and $73.2 \%(95 \% \mathrm{CI}=70.1 \%-76.0 \%)$ in the $\mathrm{LVI}(+)$ group $(p<0.001)$ (Figure 1A). There was no marked difference in the 5-year survival rates for early cancer, with rates of $93.7 \%$ (95\% CI $=92.0 \%-95.1 \%)$ in the LVI(-) group and $89.1 \%$ $(95 \% \mathrm{CI}=84.4 \%-92.4 \%)$ in the $\mathrm{LVI}(+)$ group $(p=0.18)$. In
Table IV. Clinicopathological characteristics of advanced gastric cancer cases with nodal metastases.

\begin{tabular}{|c|c|c|c|c|}
\hline Variables & Cases & $\begin{array}{l}\mathrm{LVI}(+) \\
(\mathrm{n}=451)\end{array}$ & $\begin{array}{l}\operatorname{LVI}(-) \\
(\mathrm{n}=73)\end{array}$ & $p$-Value \\
\hline Age (years) & & & & $p=0.051$ \\
\hline$<65$ & 218 & $180(39.9 \%)$ & $38(52.1 \%)$ & \\
\hline$\geq 65$ & 306 & $271(60.1 \%)$ & $35(47.9 \%)$ & \\
\hline Median & 66 & 67 & 64 & \\
\hline Range & $25-85$ & $25-85$ & $35-84$ & \\
\hline Gender $-\mathrm{n}(\%)$ & & & & $p=0.005$ \\
\hline Male & 348 & $310(68.7 \%)$ & $38(52.1 \%)$ & \\
\hline Female & 176 & $141(31.3 \%)$ & $35(47.9 \%)$ & \\
\hline $\begin{array}{l}\text { Tumor location - } \\
\mathrm{n}(\%)\end{array}$ & & & & n.p. \\
\hline $\begin{array}{l}\text { Upper third of } \\
\text { stomach }\end{array}$ & 160 & $140(31.0 \%)$ & $20(27.4 \%)$ & \\
\hline $\begin{array}{l}\text { Middle third of } \\
\text { stomach }\end{array}$ & 214 & $181(40.1 \%)$ & $33(45.2 \%)$ & \\
\hline $\begin{array}{l}\text { Lower third of } \\
\text { stomach }\end{array}$ & 150 & $130(28.8 \%)$ & $20(27.4 \%)$ & \\
\hline $\begin{array}{l}\text { Maximum tumor } \\
\text { diameter }\end{array}$ & & & & $p<0.001$ \\
\hline$<30 \mathrm{~mm}-\mathrm{n}(\%)$ & 44 & $33(7.3 \%)$ & $11(15.1 \%)$ & \\
\hline$\geq 30 \mathrm{~mm}-\mathrm{n}(\%)$ & 480 & $418(92.7 \%)$ & $62(84.9 \%)$ & \\
\hline Median - mm & 55 & 55 & 55 & \\
\hline Range & $10-212$ & $10-212$ & $16-210$ & \\
\hline $\begin{array}{l}\text { Histologic type - } \\
\mathrm{n}(\%)\end{array}$ & & & & $p=0.07$ \\
\hline Differentiated & 185 & $166(36.8 \%)$ & $19(26.0 \%)$ & \\
\hline Undifferentiated & 339 & $285(63.2 \%)$ & $54(74.0 \%)$ & \\
\hline $\begin{array}{l}\text { Depth of tumor } \\
\text { invasion }(\mathrm{T})- \\
\mathrm{n}(\%)\end{array}$ & & & & n.p. \\
\hline $\mathrm{T} 2$ & 124 & $104(23.1 \%)$ & $20(27.4 \%)$ & \\
\hline $\mathrm{T} 3$ & 107 & $89(19.7 \%)$ & $18(24.7 \%)$ & \\
\hline $\mathrm{T} 4$ & 293 & $258(57.2 \%)$ & $35(47.9 \%)$ & \\
\hline
\end{tabular}

contrast, in cases of advanced cancer, a significant difference was observed between the values of $79.8 \%$ (95\% CI=73.8\%$84.6 \%)$ in the LVI(-) group and $67.2 \%(95 \% \mathrm{CI}=63.5 \%-$ $70.7 \%)$ in the LVI $(+)$ group $(p<0.001)$ (Figure $1 \mathrm{~B}$ and $\mathrm{C})$. The OS of the LVI(+) and LVI(-) groups was analyzed for each $\mathrm{T}$ - and $\mathrm{N}$-factor, with no marked difference between the two groups for cases of early cancer, regardless of the presence of lymph node metastasis (pT1 N-: $p=0.38$, pT1 $\mathrm{N}+: p=0.75)$. Among cases of advanced cancer, there was no significant difference in the group without lymph node metastasis, but there was a difference in the survival rate only in the group with lymph node metastases (pT2-4 N-: $p=0.85$, pT2-4 N+: $p=0.005)$. The 5-year survival rate of advanced cancers with nodal metastases was $76.7 \%(95 \%$ $\mathrm{CI}=65.2 \%-84.8 \%)$ in the LVI(-) group and $60.9 \%(95 \%$ $\mathrm{CI}=56.3 \%-65.3 \%)$ in the $\mathrm{LVI}(+)$ group $(p=0.005)$ (Figure 2$)$. In the advanced-cancer group with lymph node metastasis, there was a significant difference in the maximum tumor 

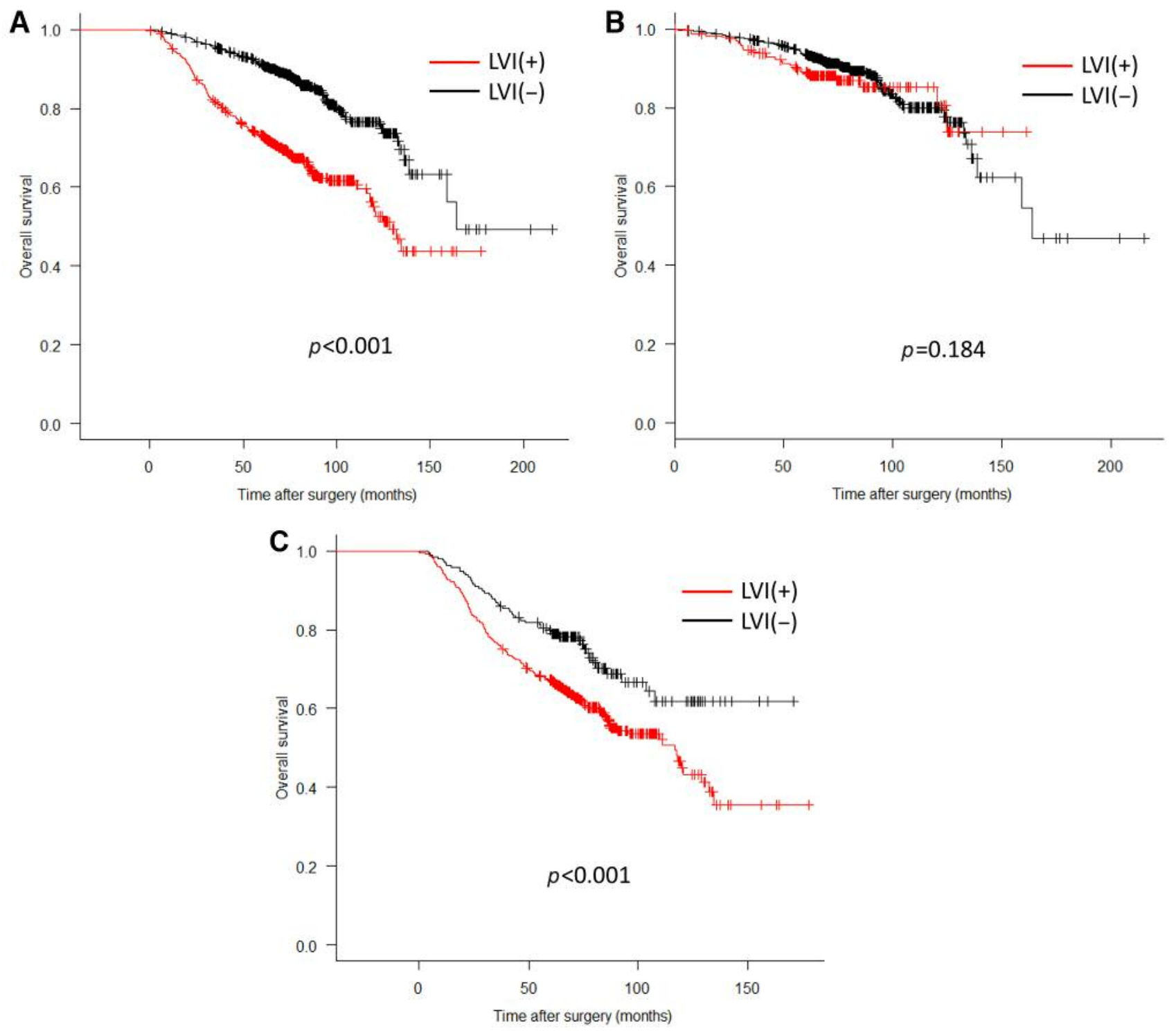

Figure 1. Impact of lymphovascular invasion (LVI) on the prognosis of patients with gastric cancer. (A) Log-rank test for all 2,090 patients; (B) Log-rank test for early gastric cancer patients (T1); (C) Log-rank test for advance gastric cancer (T2-4).

diameter between the LVI(+) and LVI(-) groups, as in all cases. There were also significantly more men in the LVI(+) group than in the LVI(-) group (Table IV).

\section{Discussion}

The Japanese guidelines and the current AJCC/UICC guidelines do not include LVI as a prognostic indicator of gastric cancer in the TNM staging system $(9,19)$. However, according to the Japanese guidelines, the presence of vascular invasion is regarded as important for determining curability after endoscopic treatment, and if lymphatic or venous invasion is positive, there is a high possibility of lymph node metastasis, indicating additional surgical resection. This evidence is based on large-scale clinical data $(20,21)$. Many prognostic factors for gastric cancer have been proposed in addition to the TNM classification, such as scoring methods using various clinical data and molecular biological data $(22,23)$. LVI, a familiar pathological finding, has also been researched regarding its impact on prognosis. Although previous small-cohort studies have also shown that LVI is an independent factor for lymph node metastasis and poor prognosis in patients with gastric cancer, Li et al. reported that the presence of LVI was 
A
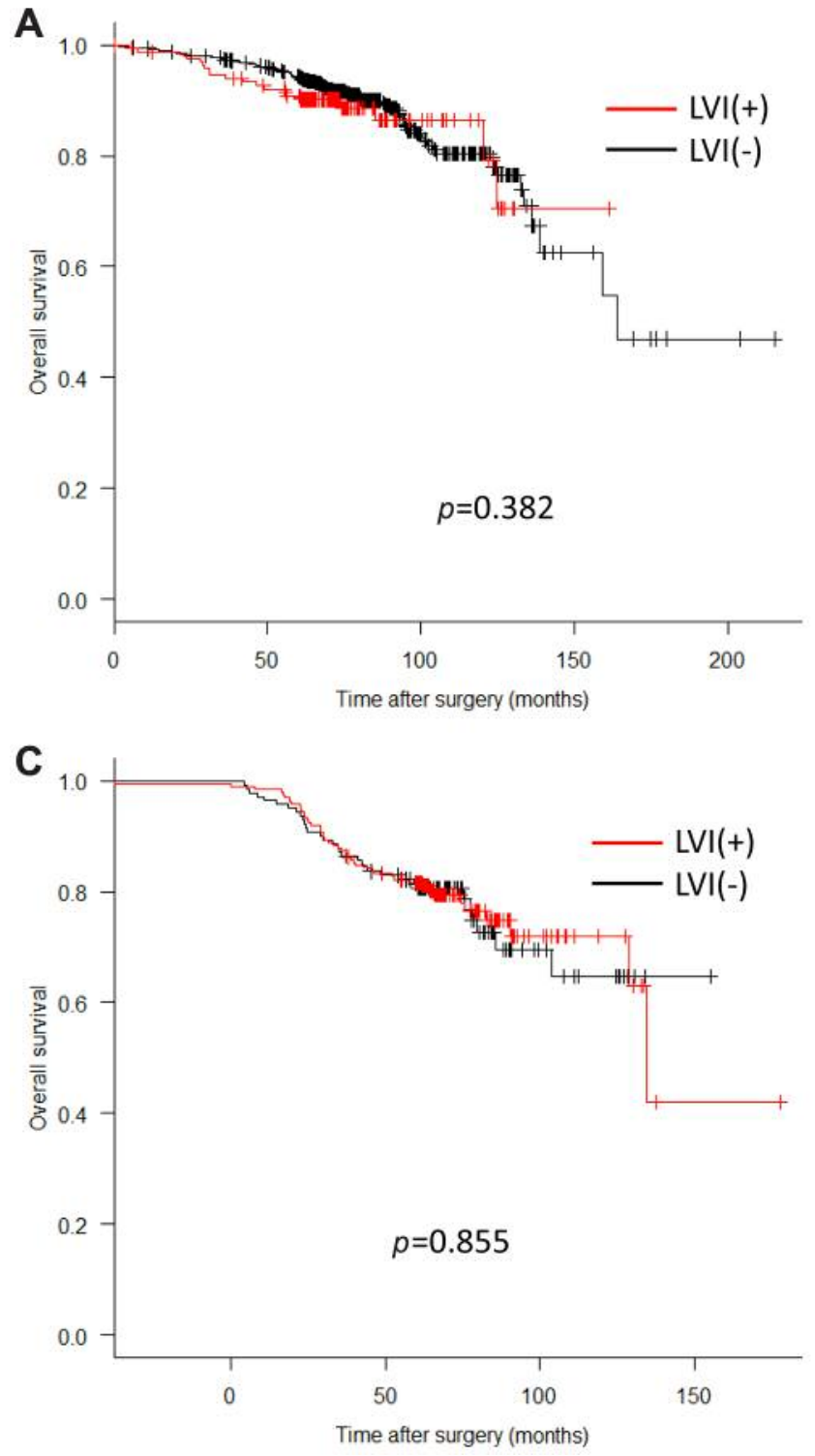
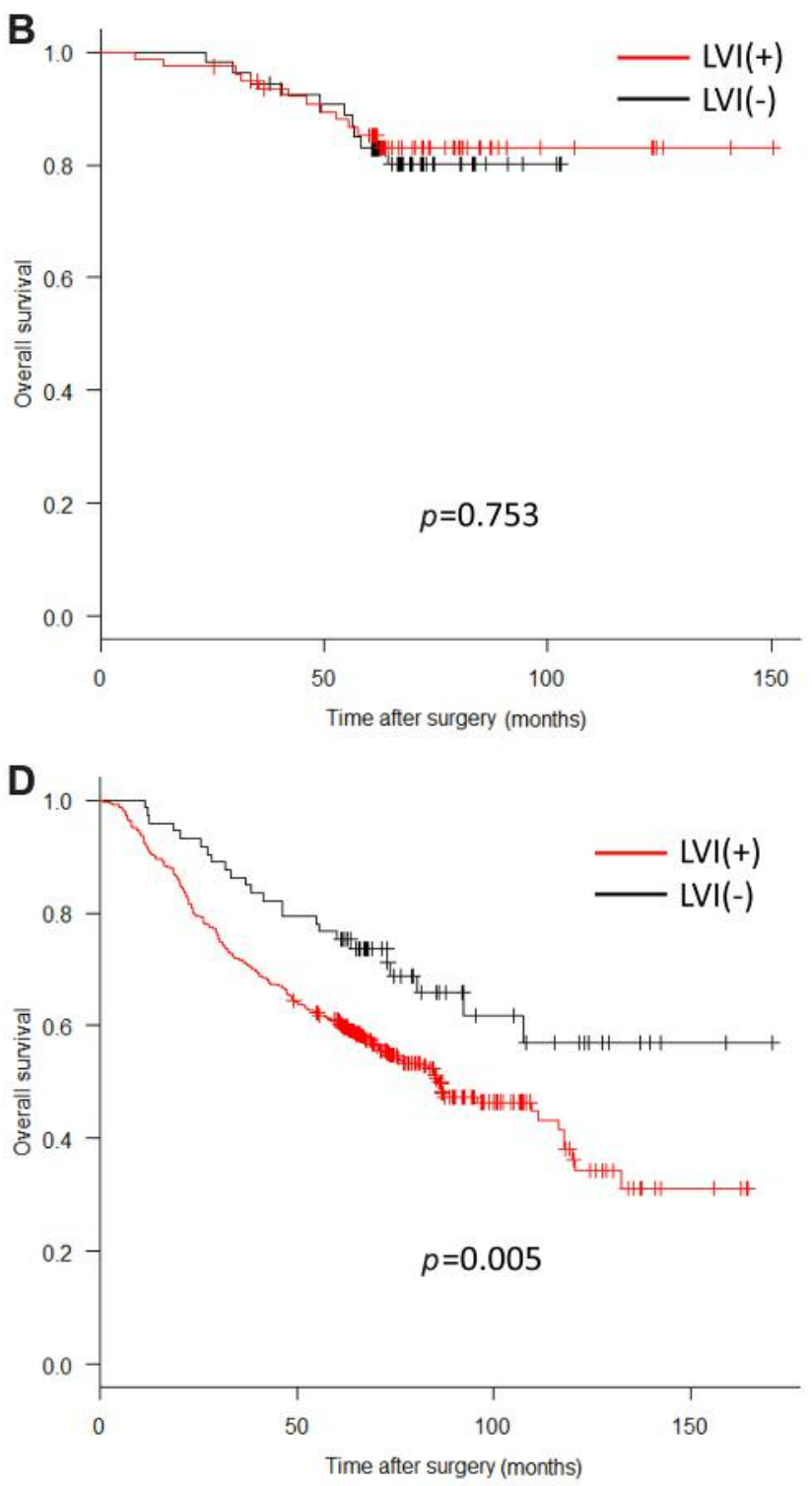

Figure 2. Prognostic significance of lymphovascular invasion (LVI) in patients stratified by each T-factor and N-factor. (A) Log-rank test for T1 N-; (B) Log-rank test for $\mathrm{T1} \mathrm{N+}$; (C) Log-rank test for T2-4 $\mathrm{N-;}$ (D) Log-rank test for $\mathrm{T2}-4 \mathrm{N+}$

significantly correlated with advanced TNM stages, and the disease-free survival (DFS) and disease-specific survival (DSS) were lower in patients with LVI than in those without LVI. A multivariate analysis also identified LVI as an independent prognostic factor for both DSS and DFS (24). However, according to the TNM staging system, N0 and N+ cases are mixed, even in the same stage. While the revision of the 8th AJCC TNM staging system has made the prognosis of each stage even more uniform, even in the same stage, the survival curves may differ among subgroups (25). We, therefore, attempted to confirm the independence of LVI prognosis and stratify the prognostic impact of LVI in large cohort studies by $\mathrm{T}$ and $\mathrm{N}$ factors rather than by TNM stage.

In the present study, LVI had no effect on the prognosis in early cancer cases. This result is thought to be due to the prognostic effects of vascular invasion being offset in many cases cured by surgical treatment, thus confirming the validity of treatment according to the above guidelines. There was no significant difference in the group with advanced cancer without lymph node metastasis. However, significant prognostic differences were observed in groups with advanced cancer with nodal metastasis. The presence of LVI has been shown to exacerbate the prognosis of advanced 
gastric cancer that already has lymph node metastasis, and this result suggests the effects of some unknown clinicopathological factors.

Although lymphatic invasion has been reported to be significantly correlated with lymph node metastasis, this study also confirmed a strong correlation with venous invasion, that should be equally evaluated (26). Histologically, the lymph nodes have abundant blood flow through the import and export lymph vessels, suggesting that metastases to the lymph nodes may be derived through routes other than the lymph flow. LVI is thought to be an early indication of lymph node and other organ metastases. However, despite the presence of lymph node metastasis, there are more than a few cases with negative vascular invasion, and in the present study, 127 of 656 cases $(19.4 \%)$ were positive for lymph node metastasis. Based on these findings, vascular invasion may indicate an invasion tendency of tumor cells rather than an initial indication of metastasis to other organs.

Poorly differentiated cells are generally known to have a strong tendency to infiltrate. However, in our study, there was no significant correlation between LVI and differentiation. It may, therefore, be necessary to interpret LVI as a completely different indicator of invasion. Many points concerning the mechanism underlying tumor cell invasion into the vascular system remain unclear, and further elucidation is required through basic research.

In Japan, the results of a randomized phase III study have suggested that conventional chemotherapy with S-1 (oral fluoropyrimidine) alone is recommended for Stage II cases, and the addition of docetaxel to S-1 therapy is the recommended treatment for Stage III cases (27). However, the present findings suggest that more effective adjuvant chemotherapy is needed for advanced cancer with lymph node metastasis with LVI, and there may be cases where the addition of docetaxel to S-1 therapy should be indicated for Stage II disease. Based on the present findings, it may be useful to establish a new risk classification system that is not limited to the current TNM classification, and incorporates LVI.

Several limitations associated with the present study warrant mentioning. This report was a retrospective, singlecenter study. Our results should be further confirmed in a multicenter prospective study. An evaluation with H\&Estained specimens is currently accepted for LVI detection. However, the histological identification of LVI using H\&E staining is subjective and may underestimate the incidence of LVI, although it has been shown that the diagnosis of LVI using H\&E staining is sufficiently reliable (16). In addition, only some sections of the resected specimen were used for the diagnosis, making it impossible to determine the LVI status of the whole tumor. This may be related to the fact that LVI may be the first indication of lymph node metastasis, but there are also many cases of lymph node metastases without LVI.

\section{Conflicts of Interest}

The Authors declare that there are no conflicts of interest with regard to this study.

\section{Authors' Contributions}

Concept and study design were conducted by H. Fujikawa and $\mathrm{T}$ Oshima. Data collection and literature search were done by $\mathrm{H}$. Fujikawa, K. Koumori, H. Watanabe, K. Kano, Y. Shimoda. Data analysis and interpretation were done by $\mathrm{H}$. Fujikawa and $\mathrm{T}$ Yamada. Interpretation of data was done by all 17 investigators. Drafting the article and figure were done by H. Fujikawa. Finally, this article was revised and approved by all 17 investigators. Thus, all Authors actively participated in this study.

\section{Acknowledgements}

The Authors thank the patients, their families, and the site staff; Brian Quinn, official editor of the Japanese Society of Internal Medicine and the Japanese Society of Surgery, for his review of this report.

\section{References}

1 Ferlay J, Soerjomataram I, Dikshit R, Eser S, Mathers C, Rebelo M, Parkin DM, Forman D and Bray F: Cancer incidence and mortality worldwide: sources, methods and major patterns in GLOBOCAN 2012. Int J Cancer 136: E359-386, 2015. PMID: 25220842. DOI: $10.1002 /$ ijc .29210

2 Hotta T: Cancer Statistics in Japan (2005) Tokyo: Foundation for Promotion Cancer Research, 2017.

3 Siewert JR, Bottcher K, Stein HJ and Roder JD: Relevant prognostic factors in gastric cancer: ten-year results of the German Gastric Cancer Study. Ann Surg 228: 449-461, 1998. PMID: 9790335. DOI: 10.1097/00000658-199810000-00002

4 Jiao XG, Deng JY, Zhang RP, Wu LL, Wang L, Liu HG, Hao XS and Liang H: Prognostic value of number of examined lymph nodes in patients with node-negative gastric Cancer. World J Gastroenterol (13): 3640-3648, 2014. PMID: 24707149. DOI: 10.3748/wjg.v20.i13.3640

5 Song YJ, Shin SH, Cho JS, Park MH, Yoon JH and Jegal YJ: The role of lymphovascular invasion as a prognostic factor in patients with lymph node-positive operable invasive breast cancer. J Breast Cancer 14(3): 198-203, 2011. PMID: 22031801. DOI: $10.4048 /$ jbc.2011.14.3.198

6 Cheng L, Montironi R, Davidson DD and Lopez-Beltran A: Staging and reporting of urothelial carcinoma of the urinary bladder. Mod Pathol 22 Suppl 2: S70-95, 2009. PMID: 19494855. DOI: 10.1038/modpathol.2009.1

7 Lim SB, Yu CS, Jang SJ, Kim TW, Kim JH and Kim JC: Prognostic significance of lymphovascular invasion in sporadic colorectal cancer. Dis Colon Rectum 53(4): 377-384, 2010. PMID: 20305435 DOI: 10.1007/DCR.0b013e3181cf8ae5

8 Japanese Gastric Cancer Association: Japanese classification of gastric carcinoma: 3rd English edition. Gastric Cancer 14(2): 101112, 2011. PMID: 21573743. DOI: 10.1007/s10120-011-0041-5

9 Japanese Gastric Cancer Association: Japanese gastric cancer treatment guidelines 2014 (ver.4). Gastric Cancer 20(1): 1-19, 2017. PMID: 27342689. DOI: 10.1007/s10120-016-0622-4 
10 Schmoll HJ, Van Cutsem E, Stein A, Valentini V, Glimelius B, Haustermans K, Nordlinger B, van de Velde CJ, Balmana J, Regula J, Nagtegaal ID, Beets-Tan RG, Arnold D, Ciardiello F, Hoff P, Kerr D, Köhne CH, Labianca R, Price T, Scheithauer W, Sobrero A, Tabernero J, Aderka D, Barroso S, Bodoky G, Douillard JY, El Ghazaly H, Gallardo J, Garin A, Glynne-Jones R, Jordan K, Meshcheryakov A, Papamichail D, Pfeiffer P, Souglakos I, Turhal $\mathrm{S}$ and Cervantes A: ESMO Consensus Guidelines for management of patients with colon and rectal cancer. a personalized approach to clinical decision making. Ann Oncol 23(10): 2479-2516, 2012. PMID: 23012255. DOI: 10.1093/annonc/mds236

11 Li P, He HQ, Zhu CM, Ling YH, Hu WM, Zhang XK, Luo RZ, Yun JP, Xie D, Li YF and Cai MY: The prognostic significance of lymphovascular invasion in patients with resectable gastric cancer: a large retrospective study from Southern China. BMC Cancer 15: 370, 2015. PMID: 25947284. DOI: 10.1186/s12885-015-1370-2.

$12 \mathrm{Bu} \mathrm{Z}$, Zheng Z, Li Z, Zhang L, Wu A, Wu X, Sun Y and Ji J: Lymphatic vascular invasion is an independent correlated factor for lymph node metastasis and the prognosis of resectable T2 gastric cancer patients. Tumour Biol 34(2): 1005-1012, 2013. PMID: 23292920. DOI: 10.1007/s13277-012-0637-3

13 Cao F, Hu YW, Li P, Liu Y, Wang K, Ma L, Li PF, Ni CR and Ding HZ: Lymphangiogenic and angiogenic microvessel density in chinese patients with gastric carcinoma: correlation with clinicopathologic parameters and prognosis. Asian Pac J Cancer Prev 14(8): 4549-4552, 2013. PMID: 24083700. DOI: 10.7314/ apjcp.2013.14.8.4549

14 Gresta LT, Rodrigues-Junior IA, de Castro LP, Cassali GD and Cabral MM: Assessment of vascular invasion in gastric cancer: a comparative study. World J Gastroenterol 19(24): 3761-3769, 2013. PMID: 23840114. DOI: 10.3748/wjg.v19.i24.3761

15 Maehara Y, Kabashima A, Koga T, Tokunaga E, Takeuchi H, Kakeji Y and Sugimachi K: Vascular invasion and potential for tumor angiogenesis and metastasis in gastric carcinoma. Surgery 128(3): 408-416, 2000. PMID: 10965312. DOI: 10.1067/msy. 2000.107265

16 Mete $\mathrm{O}$ and Asa SL: Pathological definition and clinical significance of vascular invasion in thyroid carcinomas of follicular epithelial derivation. Mod Pathol 24(12): 1545-1552, 2011. PMID: 21804527. DOI: 10.1038/modpathol.2011.119

17 Amin MB, Greene FL, Edge SB, Compton CC, Gershenwald JE, Brookland RK, Meyer L, Gress DM, Byrd DR and Winchester DP: The Eighth Edition AJCC Cancer Staging Manual: Continuing to build a bridge from a population-based to a more "personalized" approach to cancer staging. CA Cancer J Clin 67(2): 93-99, 2017. PMID: 28094848. DOI: 10.3322/caac.21388

18 Kanda Y: Investigation of the freely available easy-to-use software 'EZR' for medical statistics Bone Marrow Transplant 48(3): 452-458, 2013. PMID: 23208313. DOI: 10.1038/ bmt.2012.244v

19 Cao LL, Lu J, Li P, Xie JW, Wang JB, Lin JX, Chen QY, Lin M, Tu RH, Zheng $\mathrm{CH}$ and Huang CM: Evaluation of the Eighth Edition of the American Joint Committee on Cancer TNM Staging System for Gastric Cancer: An analysis of 7371 patients in the SEER Database. Gastroenterol Res Pract 2019: 6294382, 2019. PMID: 31097961 . DOI: $10.1155 / 2019 / 6294382$
20 Gotoda T, Yanagisawa A, Sasako M, Ono H, Nakanishi Y, Shimoda $\mathrm{T}$ and Kato $\mathrm{Y}$ : Incidence of lymph node metastasis from early gastric cancer: estimation with a large number of cases at two large centers. Gastric Cancer 3: 219-225, 2000. PMID: 11984739. DOI: 10.1007/p100011720

21 Hirasawa T, Gotoda T, Miyata S, Kato Y, Shimoda T, Taniguchi H, Fujisaki J, Sano T and Yamaguchi T: Incidence of lymph node metastasis and the feasibility of endoscopic resection for undifferentiated-type early gastric cancer. Gastric Cancer 12: 148-152, 2009. PMID: 19890694. DOI: 10.1007/s10120-0090515-x

22 Hara K, Aoyama T, Yamada T, Nakazono M, Nagasawa S, Shimoda Y, Kumazu Y, Numata M, Hayashi T, Tamagawa H, Shiozawa M, Morinaga S, Yukawa N, Rino Y, Masuda M, Ogata $\mathrm{T}$ and Oshima T: Anticancer Res 40(3): 1503-1512, 2020. PMID: 31865480. DOI: 10.21873/anticanres.14095

23 Migita K, Matsumoto S, Wakatsuki K, Kunishige T, Nakade H, Miyao S and Sho M: RNF126 as a marker of prognosis and proliferation of gastric cancer. Anticancer Res 40(3): 1367-1374, 2020. PMID: 28836056. DOI: 10.21873/anticanres.14078

24 Li P, He HQ, Zhu CM, Ling YH, Hu WM, Zhang XK, Luo RZ, Yun JP, Xie D, Li YF and Cai MY: The prognostic significance of lymphovascular invasion in patients with resectable gastric cancer: a large retrospective study from Southern China. BMC Cancer 15: 370, 2015. PMID: 25947284. DOI: 10.1186/s12885015-1370-2

25 Son T, Sun J, Choi S, Cho M, Kwon IG, Kim HI, Cheong JH, Choi SH, Noh SH, Woo Y, Fong Y, Park S and Hyung WJ: Multi-institutional validation of the 8th AJCC TNM staging system for gastric cancer: Analysis of survival data from highvolume Eastern centers and the SEER database. J Surg Oncol 120(4): 676-684, 2019. PMID: 31338834. DOI: 10.1002/ jso. 25639

26 Min BH, Byeon SJ, Lee JH, Kim KM, An JY, Choi MG, Lee JH, Sohn TS, Bae JM and Kim S: Lymphovascular invasion and lymph node metastasis rates in papillary adenocarcinoma of the stomach: implications for endoscopic resection. Gastric Cancer 21(4): 680-688, 2018. PMID: 29280035. DOI: 10.1007/s10120017-0785-7

27 Yoshida K, Kodera Y, Kochi M, Ichikawa W, Kakeji Y, Sano T, Nagao N, Takahashi M, Takagane A, Watanabe T, Kaji M, Okitsu H, Nomura T, Matsui T, Yoshikawa T, Matsuyama J, Yamada M, Ito S, Takeuchi $\mathrm{M}$ and Fujii $\mathrm{M}$ : Addition of docetaxel to oral fluoropyrimidine improves efficacy in patients with stage III gastric cancer: Interim analysis of JACCRO GC07, a randomized controlled trial. J Clin Oncol 37(15): 12961304, 2019. PMID: 30925125. DOI: 10.1200/JCO.18.01138
Received March 3, 2020

Revised March 23, 2020

Accepted March 26, 2020 